\title{
Relações raciais nas famílias brasileiras
}

\author{
Maria Carolina Tomás*
}

HORDGE-FREEMAN, Elizabeth. The color of love: racial features, stigma \& socialization in black Brazilian families. 1. ed. Austin: University of Texas Press, 2015. 311 p.

A maioria dos estudos que focam nas relações raciais na família restringe-se a análises sobre casamentos inter-raciais (SILVA, 1987; TELLES, 1993; PETRUCELLI, 2001; RIBEIRO; SILVA, 2009; LONGO, 2011; TOMÁS, 2012), sobre as diferenças socioeconômicas entre famílias com responsáveis negros e aquelas com responsáveis brancos (por exemplo, FUNDAÇÃO SEADE, 1994; CARVALHO, 1998; ALVES; CAVENAGHI; BARROS, 2001), ou buscam entender as relações entre família e outras instituições como a escola (por exemplo, FERNANDES, 2001; SANTANA; MENEZES, 2009; REZENDE; CANDIAN, 2012). Mas pouco se sabe sobre o processo de socialização e estigma no seio da família.

Analisar as relações raciais para além do casal diz respeito às próprias consequências dos casamentos inter-raciais, em que há maior possibilidade de se ter filhos com características físicas diferentes, as quais são associadas a grupos raciais distintos, tendo em vista que nossa classificação é fortemente relacionada ao fenótipo das pessoas. Alguns exemplos de estudos com foco nas relações familiares para além do casal são os de Telles (2004) e Marteleto e Dondero (2016), que analisaram resultados educacionais para irmãos e para gêmeos com classificações raciais distintas, respectivamente. Ambos os trabalhos apontaram diferenças significativas entre os irmãos. Quando se analisam irmãos, especialmente gêmeos, entende-se que se está considerando efeitos fixos da família, assumindo que os filhos têm as mesmas experiências na família e que os resultados diferenciados são fruto de experiências diversas em outras instituições, tais como a escola. Mas o estudo de

*Pontifícia Universidade Católica de Minas Gerais, Belo Horizonte-MG, Brasil (mctomas@pucminas.br). 
Hordge-Freeman alerta para as diferenças nas relações, comportamentos e expectativas dentro das famílias. 0 próprio fato de os pais classificarem diferentemente seus filhos demonstra que eles não são considerados iguais. Vale ressaltar que os autores das referidas pesquisas reconhecem essa limitação dos resultados e destacam isso em seus trabalhos. Nesse sentido, a autora ressalta que, ao estudar famílias em que há variações significativas de raça e fenótipo, é possível mostrar como as famílias estimulam diferentes interesses em seus membros de acordo com sua aparência e os auxiliam a desenvolver diferentes estratégias para seu futuro e seus resultados (p. 3-4).

Vale ressaltar que a escassez de análises intrafamiliares também se deve a uma limitação metodológica para compreensão das relações raciais de forma ampliada. Há a necessidade de se coletarem dados primários, principalmente, por meio de pesquisas qualitativas. As relações familiares captadas em surveys são limitadas e não permitem, muitas vezes, estabelecer relações de paternidade e, nem mesmo, relações entre familiares que não residem no mesmo domicílio (família estendida). Além da família, os resultados do livro demonstram o papel fundamental da vizinhança, que muitas vezes tem a mesma função da família estendida (p. 43).

0 livro de Hordge-Freeman relata os resultados de uma pesquisa que teve como área de observação, vivência e análise uma comunidade na cidade de Salvador, sob o pseudônimo de Lua Cheia. A pesquisa etnográfica teve duração de 14 meses entre 2009 e 2011, com seis semanas de follow-up em junho e julho de 2013 e mais quatro semanas em julho de 2014. Foram realizadas 116 entrevistas em profundidade com pessoas pardas e pretas de dez famílias pobres e da classe trabalhadora. A pesquisa também incluiu observação etnográfica de cinco famílias estendidas, entre as dez entrevistadas.

Ao estudar a família, e não apenas o indivíduo, a autora traz uma perspectiva da relação racial nas relações mais íntimas, considerando não apenas o casamento. A análise considera a família um lugar de se fazer, contestar e negociar raça. Explora-se a socialização racial como um processo no qual os significados e limites raciais são transmitidos. Além disso, as pessoas também aprendem a desenvolver o capital (racial) e as estratégias necessárias para convivência e gerenciamento de suas posições na sociedade (p. 3).

Os resultados do livro de Hordge-Freeman apontam diferenças de tratamento de acordo com o fenótipo por parte de familiares, inclusive mães e pais, em relação aos filhos, como nas passagens a seguir.

Minha mãe me maltratava. Ela me batia o tempo todo. Sempre que eu fazia alguma coisa... [...]. Mas eu sabia o porquê. Eu tinha a mesma cor de pele que meu pai e seu cabelo liso. Eu era branca e ela me odiava. Ela tinha inveja de mim, sua própria filha (Corina, 56) (HORDGE-FREEMAN, 2015, p. 111, tradução nossa). ${ }^{1}$

\footnotetext{
1 “[m]y mother mistreated me. She would hit me all the time. Whenever I did something... [...] But I knew why. I had the color of father's skin, his straight hair. I was white and she hated me. She was jealous of me, her own daughter (Corina, 56)".
} 
[...] meu pai expulsou meu irmão de casa quando ele tinha apenas doze anos de idade, eu acho que era pelo fato dele ser preto (David sobre seu irmão Augusto) (HORDGE-FREEMAN, 2015, p. 110, tradução nossa). ${ }^{2}$

Essas falas expressam como a família é também um espaço de estigma e racialização. Considerando a importância de se navegar na sociedade negociando a condição racial, os resultados do livro também contemplam a necessidade de se "manipular" a imagem das pessoas. Essa prática inicia-se com bebês, como nos casos em que as mães prendiam o nariz das crianças para que "afinasse", e se estende até a vida adulta com o alisamento dos cabelos. Outra preocupação é como preparar os filhos para enfrentar as dificuldades fora do lar com relação à sua raça. Dessa forma, nas conversas e nos conselhos observam-se falas diretas sobre como se apresentar, como transitar nas ruas e evitar conflitos, por exemplo. Para a autora, esse é um processo de disciplinar os corpos racializados e generificados, processo no qual as mães são a figura principal.

Hordge-Freeman ressalta que as famílias negras são complexas, contraditórias e, em geral, conscientes de suas opções limitadas; portanto, tomam as melhores decisões possíveis. Isso não significa que estas decisões e ações devam ser problematizadas, mas sim contextualizadas. Algumas mães descrevem sua adesão aos ritos racializados como resistência ou agência em uma sociedade que usa corpos racializados e generificados como uma ferramenta de poder e opressão (p. 71).

Nesse contexto, reconhece-se que o processo de socialização não tem influência apenas de fatores socioeconômicos, mas depende também da configuração racial da família. Podem ser ressaltados dois conceitos presentes no livro e que estão relacionados ao processo de racialização e socialização racial. 0 primeiro é o capital incorporado e o segundo é o de fluidez racial, associado à autoclassificação racial e à classificação de outros. Estes conceitos são tratados em seguida.

Socialização é um tema central da área de ciências sociais, desde sua fundação. Ao ler e pensar sobre o livro de Hordge-Freeman, vale ressaltar duas abordagens sobre o tema. A primeira trata de diferenças por classes, ou seja, a forma de se "criar" os filhos relaciona-se com a posição na hierarquia social. Nessa perspectiva, entende-se que as práticas, o uso de linguagem, a interação com as instituições, ou seja, a formação do capital cultural e humano das crianças se difere por sua classe social, tendo grande influência da educação materna. Um exemplo é o trabalho de Laureau (2003), em que uma das principais conclusões é a de que classe se sobrepõe à identidade racial, tendo em vista que os pais da classe média, principalmente as mães, têm como referência a abordagem de concerned cultivation. ${ }^{3}$ Não há, portanto, diferenças entre pretos e brancos nos EUA. Vale ressaltar que a autora, alguns anos depois, ao revisitar a obra reconhece essa fragilidade.

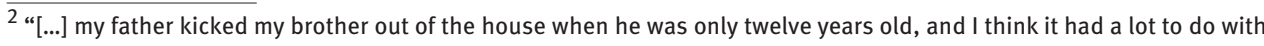
him being dark (David about his brother Augusto)".

${ }^{3}$ Tipo de criação voltada ao desenvolvimento de habilidades.
} 
A segunda perspectiva entende que há diferenças significativas por raça, seja nas preocupações dos pais, seja nas práticas e informações discutidas na família, como por exemplo o trabalho de Dow $(2012,2016)$, que discute diretamente com o estudo citado anteriormente. Os resultados apontam que as mães se preocupam em como seus filhos negros controlam sua imagem - se apresentam - e isso influencia a forma como criam seus filhos. Os participantes da pesquisa estavam preocupados, principalmente, em como seus filhos poderiam ser percebidos como criminosos. Vale destacar que a principal diferença entre estes estudos e o referido livro é que, em Salvador, as famílias estudadas não eram de classe média, mas sim dos estratos pobres da sociedade. Por outro lado, observa-se uma similaridade na argumentação da autora com o trabalho de Dow $(2012,2016)$. Nesse contexto, a socialização de filhos pardos e pretos pressupõe a incorporação não só de práticas e valores de classe, mas também de raça, tais como manipulação do fenótipo e entendimento da classificação racial.

Em The color of love observa-se uma grande preocupação em manipular o fenótipo no Brasil desde criança, como já mencionado. As práticas envolvem a preocupação com o nariz (e técnicas para afiná-lo) (p. 44, 77), com os pés (p. 78) e com os cabelos (p. 76). Ao cabelo é reservada uma discussão separada no livro, incluindo o salão de beleza: Beleza Natural (p. 93). 0 cabelo, bem como outras características e práticas de beleza, como "fazer" as unhas, é também percebido na discussão sobre corpos generificados, tendo em vista que é uma preocupação maior entre as mulheres. Além disso, a questão é também incorporada na imagem de "negras gostosas" (p. 81).

Aprofundando a análise dessas práticas, vale recorrer ao conceito de capital incorporado utilizado pela autora (p. 7). Esse conceito sugere que, quanto mais as pessoas se apresentam como tendo incorporado as predisposições e sensibilidades do grupo dominante (por meio do gosto, linguagem, vestimenta e comportamento), mais sucesso terão na sociedade. Dessa forma, as estratégias de manipulação da imagem e de apresentação (como o cabelo longo e liso) são consideradas marcas de status, tendo em vista a supremacia racial branca. Ou seja, ser branco é entendido como um status superior e, portanto, aproximar-se da classe dominante é uma forma de conquistar prestígio e sucesso, bem como afastar opiniões negativas, como se observa na fala de uma das entrevistadas: "Ah, sim, quando se é bonito(a), as pessoas são mais legais com você, elas dizem coisas mais legais sobre você. As pessoas te tratam melhor quando você é bonito(a), elas pensam que você é mais legal e são mais amigas com você [...] É por isso que uma boa aparência é importante (Lilza)" (HORDGE-FREEMAN, 2015, p. 84, tradução nossa). ${ }^{4}$

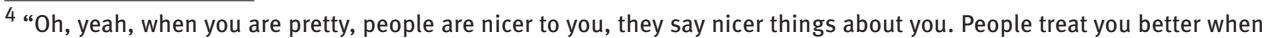
you are pretty, they think you are nicer, and they are nicer to you [...]. That is why a good appearance (boa aparência) is important (Lilza)".
} 
Outro assunto importante no contexto da socialização é a classificação racial e como as pessoas navegam e negociam sua classificação e a de terceiros. Vários estudos já mostraram que o contexto social e econômico influencia tanto a autoclassificação quanto a classificação racial de terceiros. 0 trabalho de Hordge-Freeman também demonstra como a classificação racial é fluída e necessita ser contextualizada. As pessoas aprendem a negociar a classificação racial, bem como entendem que as variações têm significados diferentes. Observa-se em uma passagem, em que a própria autora se considera preta, a dificuldade de uma criança em considerá-la dessa forma: “Não, você não é preta. Elizabeth, você não é negra. Você é morena” (HORDGE-FREEMAN, 2015, p. 146, tradução nossa). ${ }^{5}$ A autora cita vários exemplos de crianças formando o que ela chama de racial fluency (fluência racial). Para a formação dessa fluidez racial, ou seja, a sensibilidade e o conhecimento para se empregarem “corretamente" (ou o que é socialmente aceito/esperado) os termos, a família é fundamental, tendo em vista que esse aprendizado se dá no processo de socialização.

Uma questão que merece destaque nesta discussão é a preocupação da cor do parceiro nas escolhas amorosas. A cor do(a) escolhido(a) influencia a relação dos dois e sua relação com outros familiares, como pode ser observado no caso de Ivone (23 anos): "Na minha família a maioria das pessoas é preta. Me falaram que eu não poderia namorar um negro, que eu deveria namorar um branquinho. Mas eu me apaixonei pelo meu namorado que é negro" (HORDGE-FREEMAN, 2015, p. 60, tradução nossa). ${ }^{6}$ A mãe aceitou o namorado, mas uma tia a chamou de "desgraçada" por namorar uma pessoa negra, embora grande parte da família também o seja. Além de desestabilizar as relações amorosas com comentários explícitos, os parentes também acabam por reproduzir estereótipos. A autora ainda ressalta que a apresentação do(a) negro(a) à família (pode-se pensar o mesmo para o círculo de amizade) será sempre mais difícil se ele(ela) é “ninguém”, ou seja, quando não há um título, adjetivo, nível educacional atrelado a ele(ela). No caso de um casal inter-racial (ele preto e ela branca), a entrevistada descreve como as pessoas abordaram sua mãe sobre sua escolha, deixando claro que aceitariam melhor a relação se pelo menos ele fosse médico ou advogado (p. 62).

Casamentos inter-raciais têm sido interpretados como uma forma de superação de preconceito e discriminação ou como uma medida de tolerância racial (FREYRE, 2006 [1933]; PIERSON, 1942). Outros estudos entendem que a maioria dos casamentos inter-raciais ocorre em um contexto de troca de status, em que a medida mais utilizada é a escolaridade, ou seja, o(a) negro(a) teria um nível de escolaridade superior ao do(a) parceiro(a) branco(a) (DAVIS, 1941; MERTON, 1941). Pode-se acrescentar, nesse contexto, uma outra troca, por beleza (p. 64), ressaltada pela autora e também considerada por outros autores, principalmente no que concerne a erotização da mulher negra (MOUTINHO, 2004; PACHECO 2006). Uma passagem ilustrativa, apresentada no livro, encontra-se na comparação de

\footnotetext{
5 “No, no you are not preta. Elizabeth, you are not negra. You are morena".

6 "In my family, the majority of people are black. I was told I could not date a negro, I had to date a branquinho (little white guy). But I felt in love with my boyfriend and he is negro".
} 
parceiros em um casamento inter-racial: Dilson, negro e casado com uma mulher branca, é considerado o contrário dela, um homem feio (p. 62).

0 que também chama a atenção no trabalho de Hordge-Freeman é como as pessoas questionam essa visão da tolerância racial por meio da análise de taxas de casamentos inter-raciais. Segundo a autora, tanto mulheres quanto homens entrevistados citaram a relação entre um homem negro rico e uma mulher loira, como um exemplo de racismo (p. 63).

A passagem a seguir reforça o argumento da valorização dos brancos no mercado de casamento, e como isso reflete na relação desigual entre os pares: "Por muitos anos pensei que meu pai era bobo. Ele vivia como um escravo dela por anos. Mas ele não queria se separar dela. Ele estava tão apaixonado por ela. Ela era muito clara e com um cabelo preto longo (Liliane sobre seu pai)" (HORDGE-FREEMAN, 2015, p. 58, tradução nossa). ${ }^{7}$

Por fim, ressalta-se que o livro é uma grande contribuição para o entendimento das relações raciais no Brasil por considerar as relações familiares e as de vizinhança próxima, o processo de socialização, as negociações de corpos generificados e racializados, numa perspectiva que dialoga com teorias de estratificação social, teorias feministas, além de triangular classe-raça e gênero. Outros assuntos no livro são igualmente importantes, como masculinidade e aparência negra e questões relacionadas aos movimentos para valorização da beleza negra. Dessa forma, o livro merece uma leitura completa e atenta a fim de avançarmos a discussão sobre raça no Brasil, principalmente, porque as questões ali discutidas relacionam-se com observações de particularidades da sociedade brasileira, demonstrando o poder das hierarquias raciais nas relações mais intimas.

\section{Referências}

ALVES, J. E. D.; CAVENAGHI, S. M.; BARROS, L. F. W. A família DINC no Brasil: algumas características sócio-demográficas. Rio de Janeiro: Ence/IBGE, 2010 (Textos para discussão, n. 30). Disponível em: 〈http://biblioteca.ibge.gov.br/visualizacao/livros/liv49328.pdf〉.

BASTOS, J. L. et al. Diferenças socioeconômicas entre autoclassificação e heteroclassificação de cor/raça. Revista de Saúde Pública, v. 42, n. 2, p. 324-33, 2008. Disponível em: 〈http://www. scielo.br/scielo.php?script=sci_arttext\&pid=S0034-89102008000200019〉.

CARVALHO, L. M.S.S. A mulher trabalhadora na dinâmica da manutenção e da chefia domiciliar. Estudos Femininos, v. 6, n. 1, p. 7-33, 1998. Disponível em: 〈https://periodicos.ufsc.br/index. $\mathrm{php} / \mathrm{ref} /$ article/view/12032/11309>.

DAVIS, K. Intermarriage in caste societies. American Anthropologist, v. 43, n. 3, p. 376-395, 1941. Disponivel em: 〈http://www.jstor.org/stable/663138?seq=1\#page_scan_tab_contents〉.

DOW, D. M. The deadly challenges of raising African American boys navigating the controlling image of the "thug". Gender \& Society, v. 30, n. 2, p. 161-188, 2016. Disponivel em: 〈http://gas. sagepub.com/content/30/2/161.abstract>.

\footnotetext{
7 "For years I thought that my dad was a fool. He lived with her like he was her slave for years. But he did not want to separate from her. He was so in love with her. She was light with very long black hair".
} 
Racial distinctions in middle-class motherhood: ideologies and practices of African American middle-class mothers as women, mothers and parents. PhD Dissertation. UC Berkeley, Berkeley, 2012.

FERNADES, D. C. Raça, origem socioeconômica e desigualdade educacional no Brasil, uma análise longitudinal. In: 25ํㅡㄹ ENCONTRO ANUAL DA ASSOCIAÇÃO NACIONAL DE PÓSGRADUAÇÃO E PESQUISA EM CIÊNCIAS SOCIAIS. Anais... Caxambu-MG: Anpocs, 2001. Disponivel em: $<\mathrm{http}: / /$ portal.anpocs.org/portal/index.php?option=com_docman\&task=doc_ view\&gid=4564\&ltemid $=356$.

FREYRE, G. Casa grande e senzala. 51. ed. São Paulo: Editora Global, 2006.

FUNDAÇÃO SEADE. Famílias chefiadas por mulheres. Análises Especiais, n. 2, 1994.

LAREAU, A. Unequal childhoods. 1. ed. Berkeley: University of California Press, 2003.

LONGO, L. A. Uniões intra e inter-raciais, status marital, escolaridade e religião no Brasil: um estudo sobre a seletividade marital feminina, 1980-2000. Tese (Doutorado). Centro de Desenvolvimento e Planejamento Regional, Universidade Federal de Minas Gerais (Cedeplar/ UFMG), Belo Horizonte, 2011. Disponível em: 〈https://www.cedeplar.ufmg.br/demografia/ teses/2011/Luciene_2011.pdf〉.

MARTELETO, L. J.; DONDERO, M. Racial inequality in education in Brazil: a twins fixed-effects approach. Demography, online first, 2016.

MERTON, R. K. Intermarriage and the social structure. Psychiatry: A Journal of the Biology and the Pathology of Interpersonal Relations, v. 4, n. 36, p. 1-74, 1941. Disponivel em: 〈http://www. tandfonline.com/doi/abs/10.1521/00332747.1941.11022354?journalCode=upsy20 .

MOUTINHO, L. 'Raça', sexualidade e gênero na construção da identidade nacional: uma comparação entre Brasil e África do Sul. Cadernos Pagu, v. 23, p.55-88, 2004. Disponível em: 〈http://www.scielo.br/scielo.php?script=sci_arttext\&pid=S0104-83332004000200003〉.

PETRUCCELLI, J. L. Seletividade por cor e escolhas conjugais no Brasil dos 90. Estudos Afro-Asiáticos, v. 23, n. 1, p. 29-51, 2001. Disponível em: 〈http://www.scielo.br/scielo.php?script=sci_ arttext\&pid=S0101-546X2001000100002>.

PIERSON, D. Negros in Brazil: a study of race contact at Bahia. Chicago: University of Chicago Press, 1942.

RIBEIRO, C. A.; SILVA, N. do V. Cor, educação e casamento: tendências da seletividade marital no Brasil, 1960 a 2000. Dados, v. 52, n. 1, p. 7-51, 2009. Disponível em: 〈http://www.scielo.br/ scielo.php?script=sci_arttext\&pid=S0011-52582009000100001〉.

SANTANA, P. J.; MENEZES, T. A. de. Diferenças raciais no padrão de gastos com educação: uma abordagem semiparamétrica. Nova Economia, v. 19, n. 3, p. 383-405, 2009. Disponível em: 〈http://www.scielo.br/scielo.php?script=sci_arttext\&pid=S0103-63512009000300001〉.

SILVA, N. do V. Distância social e casamento inter-racial no Brasil. Estudos Afro-Asiáticos, n. 14, p. 54-83, 1987.

TELLES, E. Race in another America: the significance of skin color in Brazil. Princeton, NJ: Princeton University Press, 2004.

Racial distance and region in Brazil: intermarriage in Brazilian urban areas. Latin American Research Review, v. 28, n. 2, p. 141-162, 1993. Disponível em: 〈https://www.jstor.org/ stable/2503581?seq=1\#page_scan_tab_contents>.

TOMÁS, M. C. Interracial marriage in Brazil: a discussion about local marriage market, parents' characteristics, and household chores. Ph Dissertation. UC Berkeley, Berkeley, 2012. 


\section{Sobre a autora}

Maria Carolina Tomás é doutora em Sociologia e Demografia pela University of California, Berkeley. Professora dos cursos de graduação e pós-graduação em Ciências Sociais da Pontifícia Universidade Católica de Minas Gerais (PUC Minas).

\section{Endereço para correspondência}

Avenida Itaú, 505, 3ํandar, Bairro Dom Cabral 30535-012 - Belo Horizonte-MG, Brasil.

Recebido para publicação em 09/09/2016 Recomendado para publicação em 04/11/2016 Aceito para publicação em 06/12/2016 